\title{
The population cytogenetics of Crepis capillaris IV. The distribution of B-chromosomes in British populations
}

\author{
J. S. PARKER, G. H. JONES, ${ }^{*}$ L. A. EDGAR \& C. WHITEHOUSE* \\ School of Biological Sciences, Queen Mary and Westfield College, Mile End Road, London E1 4NS and *School of \\ Biological Sciences, University of Birmingham, P.O. Box 363, Birmingham B15 $2 T T$
}

\begin{abstract}
Populations of Crepis capillaris to the south of latitude $53^{\circ} 30^{\prime} \mathrm{N}$ in Britain are often polymorphic for the presence of $\mathrm{B}$-chromosomes. Individual plants may have $\mathrm{0B}, 1 \mathrm{~B}$ or rarely $2 \mathrm{~B}$. Eleven out of 24 southern populations carried B-chromosomes with an overall average of 14 per cent $\mathrm{B}$-containing plants in polymorphic populations. The maximum frequency of B-containing plants observed in a population was 25 per cent. In a detailed survey of Bredon Hill, Hereford and Worcester, B-chromosomes reached maximum frequencies at mid-altitudes in large populations, declining both towards the summit and in the small, isolated lowland populations. It is suggested that $\mathrm{Bs}$ in Crepis are excluded from populations growing under sub-optimal conditions. B-frequency in a population at East Wretham Heath, Norfolk, remained constant over three generations despite a very strong accumulation mechanism operating in $C$. capillaris. Selection must operate against individuals with one or more B-chromosomes to maintain this constancy.
\end{abstract}

Keywords: B-chromosomes, Crepis capillaris, geographical distribution, population structure, selection.

\section{Introduction}

B-chromosomes have been known in Crepis capillaris for many years and have been found in populations from as far apart as Switzerland (Rutishauser, 1960) and Britain (Whitehouse et al., 1981). The Bs from both these sources are small metacentric elements about one-third the length of chromosome $\mathrm{C}$, the smallest member of the standard complement, suggesting that these Bs have a common origin.

The structural similarity of these two B-accessions has recently been reinforced. C-banding studies show that repetitive DNA sequences occur on each side of the centromere in both accessions. Maluszynska \& Schweizer (1989 and personal communication) have recently demonstrated ribosomal cistrons symmetrically placed in both arms of the B from both Swissderived and British material by silver staining and by in situ hybridization of an rDNA probe. This indicates that the B has an isochromosomal organization. This conclusion has been reported by Jones et al. (1989) for British-derived B-chromosomes demonstrating symmetrical hair-pin loops in surface-spread preparations of synaptonemal complexes from pollen mother cells.
As well as structural similarity, the Bs from these two widely separated sources show common behavioural characteristics. They undergo directed somatic non-disjunction so that the floral parts usually contain a higher number of Bs than the roots or leaves (Rutishauser \& Röthlisberger, 1966; Parker et al., 1989). Bs also affect the chiasma-forming properties of the A-chromosomes, although the details of the B-effect differ between the Swiss accession (Brown \& Jones, 1976) and all the British accessions (Parker et al., 1990).

The B-chromosome's polymorphism is thus wide spread and presumably ancient in $C$. capillaris across a large proportion of the species range (Western and Central Europe; Babcock, 1947). Very little information exists on the geographical distribution of the Bs, and the structure and behaviour of B-containing populations is unknown. In view of this deficiency, and coupled with the highly effective transmission behaviour, which should lead to a strong drive in populations, it is of great interest to investigate natural populations containing B-chromosomes.

In this paper the status of B-chromosomes in British populations of Crepis capillaris is recorded. A general 
survey of Britain has been carried out as well as detailed observations of B-frequency within populations from a single small area in lowland England. In addition, a population has been followed over 3 years to assess whether changes in B-frequency occur.

\section{Materials and methods}

\section{Materials}

1 Ripe achenes were collected from between 10 and 17 individuals in populations across the southern half of Britain in 1976 (10 populations) and 1977 (8 populations). Two offspring were grown to maturity from each parent plant, and B-constitution assessed in PMCs of between 20 and 34 individuals per population. Further collections of achenes were made in 1978, from 22 populations mainly in northern England and Scotland. Two offspring per parent were again screened for B-number, giving between 20 and 28 individuals per population. Scoring was carried out on root-tips of young plants.

2 Bulk achene samples were taken from 15 plants per population in 20 populations on and around Bredon Hill, Hereford and Worcester, in August 1979. Sixty achenes per population were germinated and between 31 and 60 individuals scored for B-number by root-tip analysis.

3 Mature plants were collected at East Wretham Heath in 1978 and scored by root-tip analysis. In 1979, a leaf collection was made in May and a capitulum (bud) collection in June.

\section{Methods}

Root-tips and young leaves were treated with 0.05 per cent colchicine solution for $2 \mathrm{~h}$, fixed in $1: 3$ acetic alcohol, and stained by the Feulgen-orcein method. Capitula (buds) were fixed in 6:3:1 alcohol:chloroform:glacial acetic acid, and squashed in 2 per cent lactopropionic orcein to study meiosis.

\section{Results}

\section{B-chromosome distribution in Britain}

In the general survey, 40 populations from a wide variety of habitats were sampled from England, Wales and Scotland. A minimum of 20 plants was examined from each population to give a total of 1021 plants. B-chromosomes have been found in 11 of these populations (Table 1).

There is a very clear geographical pattern associated with the Bs which appears to reflect a North/South divide (Fig. 1). Bs were not found in the 16 populations sampled from north of latitude $53^{\circ} 30^{\prime} \mathrm{N}$, corresponding to a line through the south of Yorkshire and Lancashire. South of this line a patchwork of populations with and without Bs was found. The B-containing populations showed no further geographical partitioning, occurring both in the Western (Highland) zone in Cornwall (Boscastle) and North Wales (Porthmadog), and across the Lowland zone to East Anglia (East Wretham Heath). The Bs were found in a wide variety of habitats including both permanent and temporarysand dunes, roadside verges, permanent pasture and grassy heathland. Characteristically, populations with and without Bs are often in close proximity (e.g. Santon Downham and East Wretham Heath, Norfolk, separated by only $5 \mathrm{~km}$ ). This pattern clearly cuts across many of the obvious climatic divisions of Britain, such as those based on rainfall and both summer and winter temperatures.

The pattern established from our data, however, may not be as rigid as it appears. The B-chromosomes examined by Abraham et al. (1968), in their studies of chromosome replication patterns in Crepis, were obtained by R. A. Finch from a population at Ardgartan, Strathclyde, Scotland. In our survey, the nearest sampling site to this was at Shandon, Strathclyde, about $19 \mathrm{~km}$ to the north-west. Thus pockets of Bs may well exist to the north of latitude $53^{\circ} 30^{\prime} \mathrm{N}$, even though none were found in the 448 plants analysed by us from northern England and Scotland.

Estimates of the frequency of B-chromosomes in natural populations of Crepis capillaris will vary depending on the stage of the life-history which is studied. Thus estimates based on B-numbers in meiocytes will exceed those derived from somatic tissues such as roots or leaves as a result of accumulation due to directed non-disjunction during floral initiation (Parker et al., 1989). In this study, 18 of the populations were examined solely at meiosis and the other 22 by analysis of root-tip cells. However, if we consider only the proportion of plants with B-chromosomes all 40 populations can be compared.

Of the 1021 plants examined, only 37 (3.6 per cent) carried B-chromosomes (Table 1). The 11 B-containing populations comprised 264 individuals; in these populations the overall proportion of plants with Bs was 14 per cent. The maximum B-frequency was observed in a field-margin population from Sidmouth, Devon, in which 25 per cent of the plants carried Bs.

The B-number per plant cannot be directly assessed except in the four B-containing populations scored from root-tips. In these, $111 \mathrm{~B}$ and a single $2 \mathrm{~B}$ plant were found. In the plants scored at meiosis in PMCs, 24 had two B-chromosomes per PMC while a single 
Table 1 B-chromosome constitutions of populations of Crepis capillaris in Britain. In populations marked with an asterisk the somatic B-number was inferred from the number of Bs present in PMCs

\begin{tabular}{|c|c|c|c|c|c|c|c|c|c|}
\hline \multirow[b]{2}{*}{ Population name and code } & & \multirow{2}{*}{$\begin{array}{l}\text { Grid } \\
\text { reference }\end{array}$} & \multirow{2}{*}{$\begin{array}{l}\text { Sampling } \\
\text { year }\end{array}$} & \multicolumn{3}{|c|}{ B-number } & \multirow{2}{*}{$\begin{array}{l}\text { Plants with Bs } \\
(\%)\end{array}$} & \multirow{2}{*}{$\begin{array}{l}\text { Number Bs } \\
\text { per plant }\end{array}$} & \multirow{2}{*}{$\begin{array}{l}\text { Total } \\
\text { plants }\end{array}$} \\
\hline & & & & 0 & 1 & 2 & & & \\
\hline Ardrossan, Strathclyde & $\mathrm{AD}$ & NS 22441 & 1978 & 28 & 0 & - & 0 & - & 28 \\
\hline Arran, Strathclyde & AR & NS 020329 & 1978 & 28 & 0 & - & 0 & - & 28 \\
\hline Boscastle, Cornwall & $\mathrm{BC}^{*}$ & SX 095911 & 1977 & 18 & 2 & - & 10.0 & 0.10 & 20 \\
\hline Bredon Hill, Worcestershire & $\mathrm{BH}^{*}$ & SO 973405 & 1976 & 22 & 4 & - & 25.4 & 0.15 & 26 \\
\hline Burntisland, Fife & BI & NT 257864 & 1978 & 28 & 0 & - & 0 & - & 28 \\
\hline Bromsgrove, Worcestershire & $\mathrm{BR}^{*}$ & SO 961701 & 1976 & 30 & 0 & - & 0 & - & 30 \\
\hline Banchory, Grampian & BY & NO 692953 & 1978 & 28 & 0 & - & 0 & - & 28 \\
\hline Cirencester, Gloucestershire & $\mathrm{CC}^{*}$ & SP 015015 & 1977 & 20 & 0 & - & 0 & - & 20 \\
\hline Carleton, Cumbria & CT & NY 427527 & 1978 & 28 & 0 & - & 0 & - & 28 \\
\hline Cumnor, Oxfordshire & $\mathrm{CU}$ & SP 475043 & 1977 & 17 & 3 & - & 15.0 & 0.15 & 20 \\
\hline Coldwaltham, Sussex & $\mathrm{CW}^{*}$ & TQ 018164 & 1977 & 20 & 0 & - & 0 & - & 20 \\
\hline Dunscore, Galloway & DC & NX 805544 & 1978 & 28 & 0 & - & 0 & - & 28 \\
\hline Driffield, Gloucestershire & $\mathrm{DR}^{*}$ & SU 074997 & 1976 & 24 & 0 & - & 0 & - & 24 \\
\hline East Bridge, Suffolk & $\mathrm{EB}^{*}$ & TM 452662 & 1976 & 28 & 0 & - & 0 & - & 28 \\
\hline Edgbaston, West Midlands & ED* & SP 045837 & 1976 & 30 & 0 & - & 0 & - & 30 \\
\hline East Wretham Heath, Norfolk & EW* & TL 910885 & 1976 & 24 & 6 & - & 20.0 & 0.20 & 30 \\
\hline Farringdon, Oxfordshire & FA & SU 288961 & 1977 & 20 & 0 & - & 0 & - & 20 \\
\hline Forres, Grampian & FR & NJ 025582 & 1978 & 28 & 0 & - & 0 & - & 28 \\
\hline Fort William, Highland & FW & NN 122728 & 1978 & 28 & 0 & - & 0 & - & 28 \\
\hline Grendon, Northants & GD & SP 934923 & 1979 & 19 & 1 & - & 5.0 & 0.05 & 20 \\
\hline Girvan, Strathclyde & GV & NX 183964 & 1978 & 28 & 0 & - & 0 & - & 28 \\
\hline Ingham, Lincolnshire & $\mathrm{IN}^{*}$ & SK 963833 & 1976 & 23 & 1 & - & 4.1 & 0.04 & 24 \\
\hline Knotty Green, Bucks & KG & SU 934923 & 1979 & 18 & 2 & - & 10.0 & 0.10 & 20 \\
\hline Kingshouse, Central & $\mathrm{KH}$ & NN 563202 & 1978 & 28 & 0 & - & 0 & - & 28 \\
\hline Knighton, Powys & $\mathrm{KN}^{*}$ & SO 280720 & 1976 & 34 & 0 & - & 0 & - & 34 \\
\hline Loch Ness, Highland & LN & NH 515233 & 1978 & 28 & 0 & - & 0 & - & 28 \\
\hline Mount Hawke, Cornwall & $\mathrm{MH}^{*}$ & SW 716477 & 1977 & 20 & 0 & - & 0 & - & 20 \\
\hline Melksham, Wiltshire & MS* & ST 900640 & 1977 & 20 & 0 & - & 0 & - & 20 \\
\hline Masham, North Yorkshire & NY & SE 208826 & 1978 & 28 & 0 & - & 0 & - & 28 \\
\hline Plaidy, Grampian & PD & NJ 727553 & 1978 & 28 & 0 & - & 0 & - & 28 \\
\hline Portmadog, Gwynedd & $\mathrm{PM}^{*}$ & SH 562371 & 1976 & 27 & 1 & - & 3.6 & 0.04 & 28 \\
\hline Prenteg, Gwynedd & $\mathrm{PT}^{*}$ & SH 585414 & 1977 & 20 & 0 & - & 0 & - & 20 \\
\hline Santon Downham, Norfolk & SA & TL 821880 & 1977 & 23 & 0 & - & 0 & - & 23 \\
\hline St Boswell's, Borders & SB & NT 588309 & 1978 & 28 & 0 & - & 0 & - & 28 \\
\hline Shandon, Strathclyde & SD & NS 255868 & 1978 & 28 & 0 & - & 0 & - & 28 \\
\hline Sheffield, South Yorkshire & SF & SK 312826 & 1978 & 22 & 5 & 1 & 21.4 & 0.25 & 28 \\
\hline Sidmouth, Devon & $\mathrm{SM}^{*}$ & SY 112871 & 1977 & 15 & 5 & - & 25.0 & 0.25 & 20 \\
\hline Titton, Worcestershire & $\mathrm{TT}^{*}$ & SO 828697 & 1976 & 22 & 5 & 1 & 21.4 & 0.25 & 28 \\
\hline Winchcombe, Gloucestershire & $\mathrm{WC}^{*}$ & SP 025285 & 1977 & 20 & 0 & - & 0 & - & 20 \\
\hline Poppleton, North Yorkshire & YK & SE 554575 & 1978 & 28 & 0 & - & 0 & - & 28 \\
\hline Totals & & & & 984 & 35 & 2 & 3.6 & 0.04 & 1021 \\
\hline
\end{tabular}

plant had $4 \mathrm{~B}$. If we assume regular doubling during floral initiation these would correspond to $1 \mathrm{~B}$ and $2 \mathrm{~B}$ somatic constitutions, respectively, but this cannot necessarily be assumed (Parker et al., 1989). Thus summing these observed and inferred figures gives a provisional total of $35 \mathrm{1B}$ plants and only two $2 \mathrm{~B}$ plants, giving an average of $0.15 \mathrm{Bs}$ per plant in the polymorphic populations. Thus the B-polymorphism of Crepis capillaris in Britain is very widespread geographically, but Bs reach only low frequencies in any population, and most $\mathrm{B}$-containing plants have only a single B-chromosome. This pattern may be repeated in other parts of the range of the species. In 150 plants from six French populations only one plant 


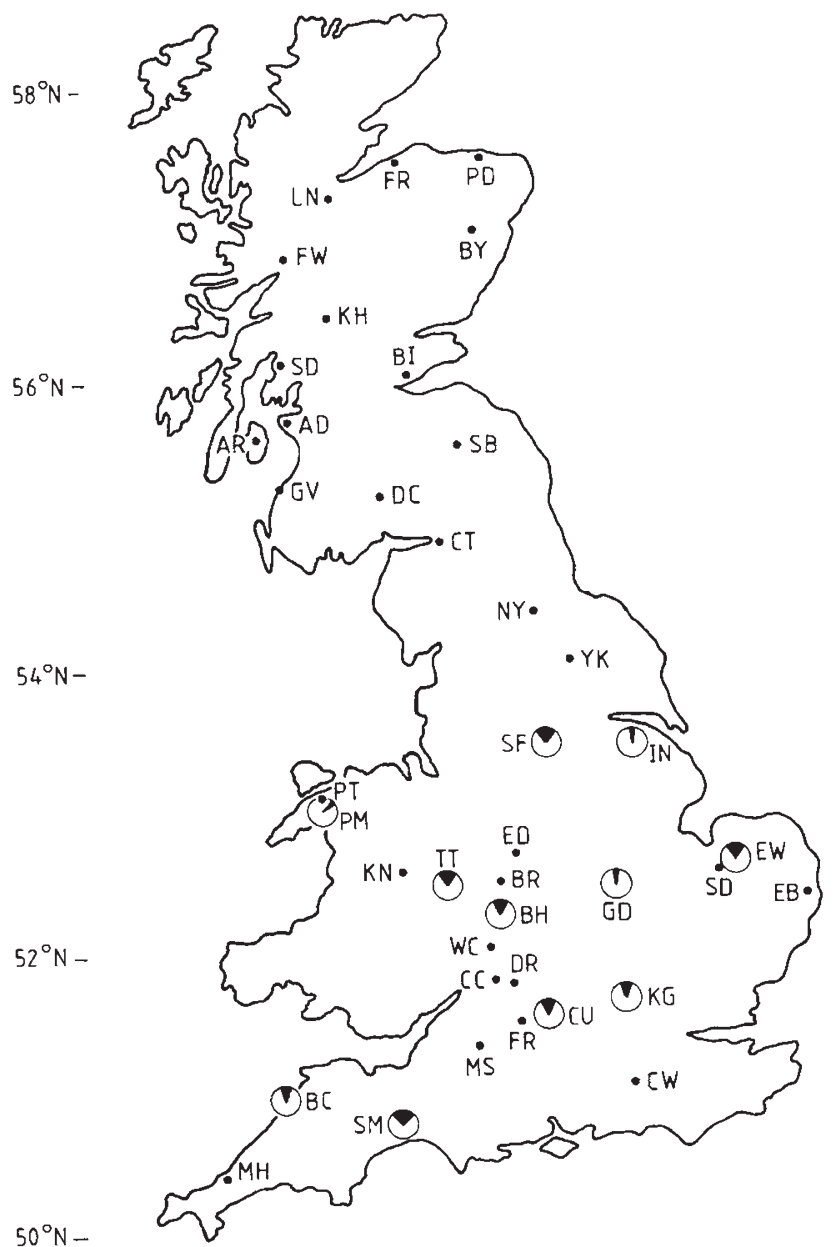

Fig. 1 Location of the 40 populations of Crepis capillaris in Britain scored for B-frequency. The proportion of B-chromosome containing plants in polymorphic populations is shown by the size of the black segment.

containing Bs was found: a plant with 2B PMCs from St Jean Trolimon in Finistère.

\section{B-chromosome distribution on Bredon Hill}

The extensive survey of natural populations for the presence of B-chromosomes thus indicates that Bs are limited to southern Britain, but even in this region their distribution is markedly patchy. A more intensive study of an area where Bs are relatively frequent has, therefore, been carried out in an attempt to identify any factors contributing to this patchu ork distribution.

The area chosen was Bredon Hill (Hereford \& Worcester), an isolated outlier of the Cotswold Hills rising from the valley of the River Avon and roughly $6 \times 5 \mathrm{~km}$ in extent. The hill rises from a plain of about $50 \mathrm{~m}$ above sea level to about $300 \mathrm{~m}$ at the summit.
Samples were taken along four transects up the hill, a total of 20 populations in all (Fig. 2). The transects had different aspects: Elmley Castle (EC) north-facing, Ashton under Hill $(\mathrm{AH})$ east, Kemerton $(\mathrm{KE})$ south, and Bredon's Norton (BN) south-west. Four samples were also taken from near the summit (SU) and one from the plain near Beckford (BE) to the south-east (Fig. 2). The minimum sample size was 31 individuals (Beckford) and the mean number of individuals sampled per population was 54.1. A total of 1082 plants from this area were scored for B-number by root-tip analysis of seedlings (Table 2).

B-chromosomes were found in 16 of the 20 populations on and around Bredon Hill (Fig. 2). The overall average proportion of plants with Bs in these populations, however, was only 8.2 per cent, rising to 10.4 per cent if populations without B-chromosomes are excluded (cf. 3.6 per cent and 14 per cent in the national survey). In addition, the great majority of B-containing plants carry a single $\mathrm{B}(82 / 89)$ in somatic tissues, with the remaining seven having $2 \mathrm{Bs}$. The average B-frequency over this area is then only 0.089 per plant. There is great heterogeneity in B-frequency between the 20 samples. The proportion of plants with Bs ranges from 0 to 38.2 per cent (EC 2) while the mean B-number per plant ranges from 0.0 to 0.4 .

The total altitudinal range studied was $46-298 \mathrm{~m}$. If the mean B-number per plant is plotted against altitude then a clear pattern emerges. In each of the four transects, the peak B-frequency lies in a relatively narrow band at mid-altitude, between $120(\mathrm{BN})$ and $197 \mathrm{~m}(\mathrm{KE})$, with lower B-frequencies both above and below this band (Fig. 3). This altitudinal band also encompasses all six populations with mean frequencies greater than 0.10 per plant, while all seven populations growing above $215 \mathrm{~m}$ had B-frequencies lower than 0.055 per plant.

A direct correlation of B-frequency with altitude, however, must be treated with some caution since the populations sampled also differ in size. They may be roughly categorized as Small $(0-25$ individuals; 5 populations), Medium (26-50; 6 populations), and Large (51-100; 9 populations) (Table 2). B-frequencies for these three classes are $0.028,0.049$ and 0.148 , respectively. Thus B-frequency may be partly dependent on population size although population size itself may be a reflection of the suitability of the habitat for C. capillaris. Under the environmental conditions prevailing on and around Bredon Hill, the low altitude populations are small and isolated in predominantly arable areas, while at higher altitudes large populations flourish in permanent sheep-grazed pastures. Within the high frequency zone, two aberrant populations are found: KE2 without Bs and AH3 with only 0.019 Bs 
Fig. 2 Contour map of Bredon Hill showing the $C$. capillaris collection sites and the proportion of B-containing plants (black sectors). (•) Populations with no B-chromosomes.

per plant. The former is a very small, isolated, population while the latter is of medium size.

Despite the variability introduced by population size, it seems possible that B-frequency is indeed correlated with altitude. The highest B-frequencies occur in the large populations at the lower altitudinal levels of the sheep-pastures; towards the summit the equally large populations, also in permanent pasture, have much lower B-frequencies. The coincidence of this pattern in the four transects with their distinctive aspects reinforces this conjecture.

\section{B-chromosomes stability over years}

The proportion of $\mathrm{B}$-containing individuals in the population at East Wretham Heath was estimated on four separate occasions between 1976 and 1979 (Table 3). The first study was made of achenes collected in 1976, while one study in 1978 and two in 1979 were made on plants in situ. Since C. capillaris is an annual with one generation per year, this sampling scheme represents three consecutive generations, although in different phases of the life cycle.

In the 1976 seed collection there were 20 per cent $\mathrm{B}$-containing individuals all with a single $\mathrm{B}(6 / 30)$. In 1978 , a collection of mature individuals, which had initiated flower buds, gave a value of 17.9 per cent plants with $1 \mathrm{~B}(5 / 28)$. The first collection made in May 1979 , however, was distinctive. It was very large (105 individuals) including all plants growing within the sampling area, from which leaves were removed in situ. In this collection, 26.6 per cent of plants had Bs (28/ 105 ) and four $2 \mathrm{~B}$ plants were detected. The fourth col- lection was made in June 1979 when capitula from 41 plants were sampled. In this collection 17 per cent of plants contained Bs (7/41), and in all the PMCs scored 2Bs were found. Assuming that a high frequency of accumulation operates in nature as in the experimental glasshouse, we may infer that these plants all contained $1 \mathrm{~B}$ in somatic tissues. The difference between the May and June samples, however, is not significant $\left(\chi^{2}=\right.$ $1.46 ; P>0.05)$.

Over these three generations, B-chromosome frequency remains roughly constant at about 20 per cent. The high B-frequency obtained from leaf samples perhaps indicates that plants with $2 \mathrm{Bs}$ die before flowering, fail to flower, or are delayed in flowering relative to $0 \mathrm{~B}$ and $1 \mathrm{~B}$ individuals. Although $\mathrm{B}$-number may be partly controlled in this manner, this is unsufficient to balance the effects of B-accumulation due to directed non-disjunction into the flowers. Strong selection against both $2 \mathrm{~B}$ and $1 \mathrm{~B}$ individuals must occur at some stage in the life cycle.

\section{Discussion}

B-chromosomes are a widespread component of the genetic system of Crepis capillaris. They have been reported from Germany (Barthelmiss \& Bauchinger, 1962), Switzerland (Rutishauser, 1960), France and Britain (Parker et al., 1989; this paper). Crepis capillaris has also spread widely around the world as an adventive, and Bs have also been dispersed: Bs occur in plants collected in north India (Kaushal \& Mehra, 1976). On the basis of morphology, DNA composition, and pre-meiotic and meiotic behaviour it is 
Table 2 B-chromosome constitutions of populations of C. capillaris from Bredon Hill, Worcestershire. Population sizes are given as Small (S, 0-25 plants), Medium (M, 26-50 plants) and Large (L, 51 + plants)

\begin{tabular}{|c|c|c|c|c|c|c|c|c|}
\hline \multirow[b]{2}{*}{ Population } & \multirow{2}{*}{$\begin{array}{l}\text { Population } \\
\text { size }\end{array}$} & \multirow{2}{*}{$\begin{array}{l}\text { Altitude } \\
\text { (m) }\end{array}$} & \multicolumn{3}{|c|}{ Number of Bs } & \multirow{2}{*}{$\begin{array}{l}\text { Total } \\
\text { plants }\end{array}$} & \multirow{2}{*}{$\begin{array}{l}\text { B-frequency } \\
\text { per plant }\end{array}$} & \multirow{2}{*}{$\begin{array}{l}\text { Plants with } \\
\text { Bs }(\%)\end{array}$} \\
\hline & & & 0 & 1 & 2 & & & \\
\hline \multicolumn{9}{|c|}{ Ashton under Hill } \\
\hline AH1 & $\mathrm{S}$ & 90 & 49 & 4 & 0 & 53 & 0.075 & 7.6 \\
\hline $\mathrm{AH} 2$ & $\mathrm{~L}$ & 125 & 34 & 16 & 2 & 52 & 0.385 & 34.6 \\
\hline AH3 & M & 185 & 52 & 1 & 0 & 53 & 0.019 & 1.9 \\
\hline $\mathrm{AH} 4$ & M & 220 & 57 & 0 & 0 & 57 & 0 & 0 \\
\hline \multicolumn{9}{|c|}{ Elmley Castle } \\
\hline EC1 & $\mathrm{S}$ & 70 & 53 & 0 & 0 & 53 & 0 & 0 \\
\hline $\mathrm{EC} 2$ & $\mathrm{~L}$ & 150 & 34 & 20 & 1 & 55 & 0.400 & 38.2 \\
\hline EC3 & $\mathrm{L}$ & 170 & 49 & 7 & 1 & 57 & 0.158 & 14.0 \\
\hline \multicolumn{9}{|c|}{ Bredon's Norton } \\
\hline BN1 & M & 120 & 46 & 6 & 1 & 53 & 0.151 & 13.2 \\
\hline $\mathrm{BN} 2$ & $\mathrm{~L}$ & 140 & 53 & 5 & 2 & 60 & 0.150 & 11.7 \\
\hline BN3 & M & 205 & 52 & 5 & 0 & 57 & 0.088 & 8.8 \\
\hline BN4 & $\mathrm{L}$ & 250 & 59 & 0 & 0 & 59 & 0 & 0 \\
\hline \multicolumn{9}{|l|}{ Kemerton } \\
\hline KE1 & $\mathrm{S}$ & 60 & 58 & 2 & 0 & 60 & 0.033 & 3.3 \\
\hline KE2 & $\mathrm{S}$ & 155 & 59 & 0 & 0 & 59 & 0 & 0 \\
\hline KE3 & $\mathrm{L}$ & 195 & 50 & 7 & 0 & 57 & 0.123 & 12.3 \\
\hline KE4 & $\mathrm{L}$ & 235 & 40 & 2 & 0 & 42 & 0.048 & 4.8 \\
\hline \multicolumn{9}{|l|}{ Beckford } \\
\hline $\mathrm{BE}$ & $\mathrm{S}$ & 45 & 30 & 1 & 0 & 31 & 0.032 & 3.2 \\
\hline \multicolumn{9}{|l|}{ Summit } \\
\hline SU1 & M & 250 & 53 & 1 & 0 & 54 & 0.019 & 1.9 \\
\hline SU2 & $\mathrm{M}$ & 175 & 56 & 1 & 0 & 57 & 0.018 & 1.8 \\
\hline SU3 & $\mathrm{L}$ & 285 & 55 & 1 & 0 & 56 & 0.018 & 1.8 \\
\hline WU4 & $\mathrm{L}$ & 298 & 54 & 3 & 0 & 57 & 0.053 & 5.3 \\
\hline Totals & & & 993 & 82 & 7 & 1082 & 0.089 & 8.2 \\
\hline
\end{tabular}

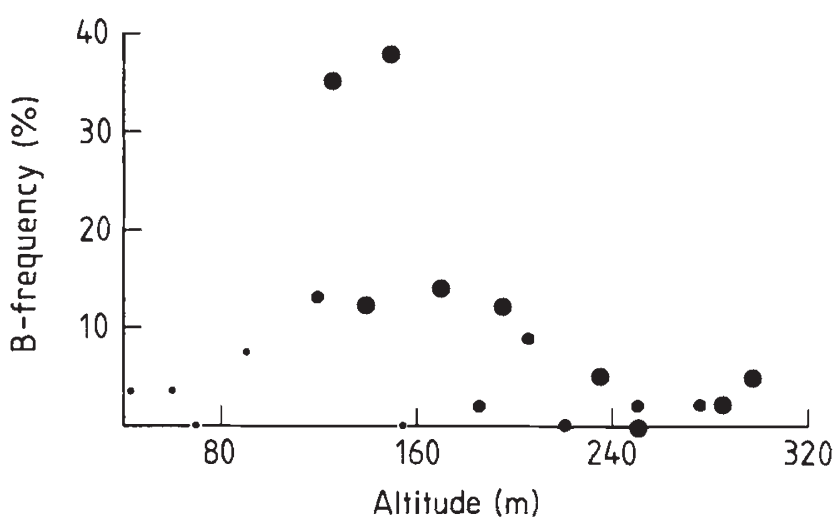

Fig. 3 The relationship between altitude and proportion of plants containing B-chromosomes on Bredon Hill. Small, medium and large populations are indicated by the size of the circle. clear that the Swiss and British Bs are very similar and may have a common and presumably ancient origin (Rutishauser \& Röthlisberger, 1966; Jones et al., 1989; Maluszynska \& Schweizer, 1989; Parker et al., 1989). Despite numerous experimental studies of the B-chromosomes of this species, little is known of the basic population parameters of the B-polymorphism.

The survey of B-chromosome distribution in Britain indicates that Bs are found only in populations in the southern half of the range. No populations with Bs were found to the north of Yorkshire. However, the Bs studied by Abraham et al. (1968) were derived from a population collected in the Scottish lowlands. If not entirely absent from northern Britain then, Bs must be present at a much lower frequency than in the south since none was found in the 448 plants of northern origin in the present study. 
Table 3 B-chromosome constitution of samples taken from a population at East Wretham Heath, Norfolk, on four separate occasions spanning three generations. In the June 1979 samples somatic B numbers are inferred from the numbers present in PMCs

\begin{tabular}{|c|c|c|c|c|c|c|}
\hline \multirow[b]{2}{*}{ Sample date } & \multirow[b]{2}{*}{ Material sampled } & \multicolumn{3}{|c|}{ Number of Bs } & \multirow{2}{*}{$\begin{array}{l}\text { Total } \\
\text { plants }\end{array}$} & \multirow{2}{*}{$\begin{array}{l}\text { Plants } \\
\text { with Bs (\%) }\end{array}$} \\
\hline & & 0 & 1 & 2 & & \\
\hline August 1976 & Achenes & 24 & 6 & 0 & 30 & 20.0 \\
\hline May 1978 & Mature plants & 23 & 5 & 0 & 28 & 17.9 \\
\hline May 1979 & Leaves in population & 77 & 24 & 4 & 105 & 26.7 \\
\hline June 1979 & Capitula in population & 34 & 7 & 0 & 41 & 17.1 \\
\hline
\end{tabular}

It is remarkable that closely similar patterns of B-distribution in Britain have been recorded in two other species with nationwide distribution. In the plant Rananculus ficaria, B-chromosomes reach their highest frequencies in diploid populations from the south-west of England and are scattered through the south-east of England (Gill et al., 1972). No B-chromosomes have been recorded from populations growing to the north of Manchester $\left(53^{\circ} 30^{\prime} \mathrm{N}\right)$. Similarly, B-chromosomes are a common feature of southern populations of the mottled grasshopper Myrmeleotettix maculatus, but Bs have not been located in populations to the north of the Humber (Hewitt, 1973) $\left(53^{\circ} 45^{\prime} \mathrm{N}\right)$. Is the coincidence of the cut-off point for B-chromosomes in populations of these three dissimilar organisms purely fortuitous, or does it represent some feature of the environment jointly affecting all three, or perhaps the post-glacial history of colonization of Britain?

In $M$. maculatus, B-chromosomes are found in populations in the south and east of Britain which are climatically more optimal for grasshoppers (Hewitt, 1973). Correlations of B-frequencies with temperature gradients have been demonstrated in East Anglia (Hewitt \& Brown, 1970) and, on a small scale, with microclimate on a disused lead mine in Wales (Hewitt \& Ruscoe, 1971). Perhaps Bs are tolerated only in populations which are not under severe selective stress.

In $C$. capillaris, B-distribution on Bredon Hill suggests that altitude, or some associated environmental variable, is influential in determining frequency. Maximal B-frequencies are attained at mid-altitudes, with a decline towards the summit and into the lowlands. It is possible that the effects of population size and associated factors are confounding here. Small populations have low B-frequencies, or are without Bs entirely. Such populations are likely to be relatively inbred, and a notable feature of B-systems is that they are found only in outbreeders (Jones \& Rees, 1982). The small populations of $C$. capillaris at low altitudes also exist in transient habitats, such as road verges, field margins and waste land, in less than optimal conditions for the species, and are probably subject to a regular cycle of extinction and recolonization with low numbers of founders. The likelihood of B-loss by sampling is high under such a regime. These stochastic processes may play a large part in maintaining the patchwork of $0 \mathrm{~B} /+\mathrm{B}$ populations in the polymorphic part of the range. In the large pasture populations, which stretch continuously to the summit, and where there is relative environmental stability, B-frequency declines with increasing altitude on all four transects. In terms of average temperature, $100 \mathrm{~m}$ of altitude corresponds roughly to a decline of $1.5^{\circ} \mathrm{C}$. The average temperature also declines with increasing latitude, and thus latitudinal and altitudinal clines in B-frequency may both reflect temperature-dependence.

The B-polymorphism of $C$. capillaris consists essentially of two morphs $-0 \mathrm{~B}$ and $1 \mathrm{~B}$. Plants with $2 \mathrm{Bs}$ have been found in seed samples and in mature plants at East Wretham Heath but are rare. The Crepis B, however, has a very powerful accumulation mechanism into meiocytes, and transmission through both pollen and eggs is about 0.8 per $\mathrm{B}$, rather than the expected 0.5 (Parker et al., 1989). The expectation is that Bs should increase in frequency in the population over generations, giving both more plants with B-chromosomes and higher numbers of Bs in any one individual. This is not the case; B-frequency seems to remain fairly constant over generations, at least in the EWH population. The limited data from this population suggests that $2 \mathrm{~B}$ plants fail to flower, which will reduce overall B-number. The selection pressure is insufficient to maintain the equilibrium in the face of enhanced transmission, and selection must operate against $1 \mathrm{~B}$ individuals at some phase of the life-cycle. Robinson \& Hewitt (1976) have shown that stability of B-frequency between generations of Myrmeleotettix maculatus is maintained by a combination of drive into functional 
eggs and subsequent drag by selective death of B-containing embryos. Observations of B-behaviour throughout the life cycle of $C$. capillaris in populations on Bredon Hill and East Wretham Heath will be presented in a subsequent paper.

\section{References}

ABRAHAM, S., AMES, I. H. AND SMITH, H. H. 1968. Autoradiographic studies of DNA synthesis in the B-chromosomes of Crepis capillaris. J. Heredity, 59, 297-299.

BABCOCK, E. B. 1947. The Genus Crepis. University of California Press, Berkeley and Los Angeles.

BARTHELMISS, A. AND BAUCHINGER, M. 1962. B-chromosomes in Crepis capillaris. Genetica, 33, 165-166.

BROWN, L. M. AND JONES, R. N. 1976. B-chromosomes effects at meiosis in Crepis capillaris. Cytologia, 41, 493-506.

GILL, J. J. B., JONES, B. M. G., MARCHANT, C. J., MCLEISH, J. AND OCKENDEN, D. J. 1972. The distribution of chromosome races of Ranunculus ficaria L. in the British Isles. Ann. Bot., 36, 31-47.

HEwITT, G. M. 1973. Evolution and maintenance of B-chromosomes. Chromosomes Today, 4, 351-369.

HEWITT, G. M. AND BROWN, F. M. 1970. The B-chromosome system of Myrmeleotettix maculatus V. A steep cline in East Anglia. Heredity, 25, 363-371.

HEWITT, G. M. AND RUSCOE, C. 1971. Changes in the microclimate correlated with a cline for B-chromosomes in the grasshopper Myrmeleotettix maculatus (Thumb)
(Orthoptera: Acrididae). J. Anim. Ecol., 40, 753-765. JONES, R. N. AND REES, H. 1982. B-chromosomes. Academic Press, London.

JONES, G. H., WHITEHORN, J. AND ALBINI, s. 1989. Ultrastructure of meiotic pairing in $\mathrm{B}$-chromosomes of Crepis capillaris 1. 1B and 2B PMCs. Genome, 32, 611-621.

KAUSHAL, P. S. AND MEHRA, P. N. 1976. Chromosomal instability in Pterotheca falconeri. Nucleus, 19, 47-49.

MALUSZYNSKA, J. AND SCHWEIZER, D. 1989. Ribosomal RNA genes in B-chromosomes of Crepis capillaris detected by non-radioactive in situ hybridisation. Heredity, 62, 59-66.

PARKER, J. S., JONES, G. H., EDGAR, L. AND WHITEHOUSE, C. 1989. The population cytogenetics of Crepis capillaris II. The stability and inheritance of B-chromosomes. Heredity, 63, 19-27.

PARKER, J. S., JONES, G. H., EDGAR, L. AND WHITEHOUSE, C. 1990. The population cytogenetics of Crepis capillaris III. B-chromosomes effect on meiosis. Heredity, 67, 377-385.

ROBINSON, P. M. AND HEWITT, G. M. 1976. Annual cycles in the incidence of B-chromosomes in the grasshopper Myrmeleotettix maculatus (Acrididae: Orthoptera). Heredity, 36, 399-412.

Rutishauser, A. 1960. Fragment Chromosomen bei Crepis capillaris. Beih. Z. Schweiz Forstwereins, 30, 93-106.

RUTISHAUSER, A. AND RÖTHLISBERgER, E. 1966. Boosting mechanism of B-chromosomes in Crepis capillaris. Chromosomes Today, 1, 28-30.

WHITEHOUSE, C., EDGAR, L. A., JONES, G. H. AND PARKER, J. S. 1981. The population cytogenetics of Crepis capillaris I. Chiasma variation. Heredity, 47, 95-103. 